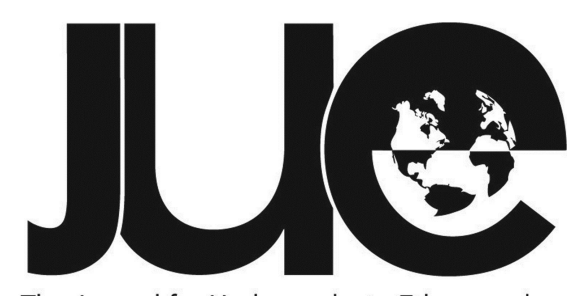

The Journal for Undergraduate Ethnography

\title{
Just for Fun: Talk and Tactical Shooting in Southern Saskatchewan
}

\section{Christi Hubbs}

University of Regina, hubbs20c@uregina.ca

\section{ABSTRACT}

This article gives an ethnographic account of a group of Canadians who feel invested in recreational gun use, by examining their narratives and social relations created through the practice of shooting "just for fun." This is the result of fieldwork with a group of men who practice a specialized form of marksmanship called tactical shooting in southern Saskatchewan. In this research, narrative "talk" emerges as a social glue for tactical shooters, which I analyze using Michael Herzfeld's concepts of poetics and performance. These men's storytelling is discussed as a means of collaboratively creating and enacting a worldview and a sense of shared identity. I argue that stories enable shooters to build a sense of togetherness in a context where they often feel misunderstood, both by more conventional shooters and by broader society. In this group, tactical shooting is not merely a leisurely pursuit - something done "just for fun" - it is a social occasion for dramatic storytelling which produces distinctive selves, relations, and comradeship.

Keywords: tactical shooting, poetics, performance, identity, masculinity 
"Shooting is a practical skill, it can protect you, put food on the table," Ray said, then gestured to Jon holding a high calibre "elephant" gun. "But that's just for fun!"

t was an unseasonably warm October night. The three of us sat comfortably in our sweatshirts, our campsite - nestled on a section of south Saskatchewan Crown land (land owned by the Canadian state) - so dark that we could barely see one another. The trees surrounding us shook, and we waited for the burst of wind to subside before listening for coyote calls.

Ray, Jon, and I were lounging against a sturdy log as we listened to the melodic coyote howls from the hills surrounding us. Ray had just quieted his handheld animal call simulator, his most recent effort to draw the canines' attention with the device's startlingly realistic locator howl. We were picking burrs off our clothing from an afternoon of shooting in the tall grass (Figure 1), and were partway through a mickey of liquor when we first heard the animals' approach. When Ray suggested we see how close we could draw them in, we turned off our lights and tried to muffle our presence. We sipped from tin camp mugs and munched on Doritos, occasionally using the animal call to coerce the two groups of coyotes into "talking" to one another. The objective, I was informed, was simply to communicate with them, as both men emphatically whispered "no" when I asked if they were going to shoot.

"Not unless something goes wrong!" Jon, my boyfriend, clarified. I nodded, wondering at the ease the men displayed at the prospect of wild dogs approaching us. I gathered that the two shooters - a term my informants used to describe themselves - who both had years of outdoor experience, would alert me if something indeed "went wrong." A rifle leaned against a tree, unloaded but within arm's reach, ready to be stuffed with one of the multiple "mags" (magazines) of bullets hanging from pouches on the men's belts. The other gun, a much fancier "elephant gun" on loan from another shooter, was locked safely in the car.

Drinking and communicating with coyotes was how we whiled away the evening until the wind grew too loud to hear the animals and dazzling northern lights drew our attention upwards. Although we agreed to be quiet so as not to scare the dogs away, my companions whispered frequently, as though unwilling to completely stifle the stream of talk that overlaid our time together. This talk - congenial and at first glance inconsequential - would grow in significance to me throughout my subsequent fieldwork. But, right then, it was just one part of our evening spent in conversation with the natural world, a long stretch of inactivity characterized by easy sharing of supplies and even easier sharing of stories. While Jon and Ray had been "showing me shooting" throughout the day, I later reflected that this evening was my first real introduction to their leisure world of tactical shooting.

This article is the result of two months of fieldwork conducted with recreational tactical shooters in southern Saskatchewan. From October to November 2015, I accompanied a loose group of friends who engaged in tactical shooting in their spare time, as they met with one another to shoot and "shoot the shit." Throughout this fieldwork, I noticed a strong prevalence of specific forms of narrative talk linking these shooters' practices. This article examines the performance of such talk and the "poetics" (Herzfeld 1985) that constitute it, through an ethnographic exploration of tactical shooting in southern Saskatchewan. Performance and poetics, which are intertwined in my informants' collaborative narratives, are organizing concepts that can help us make sense of the social significance of discussions which, to outsiders, may not seem "sensible." This talk, which at first might seem 


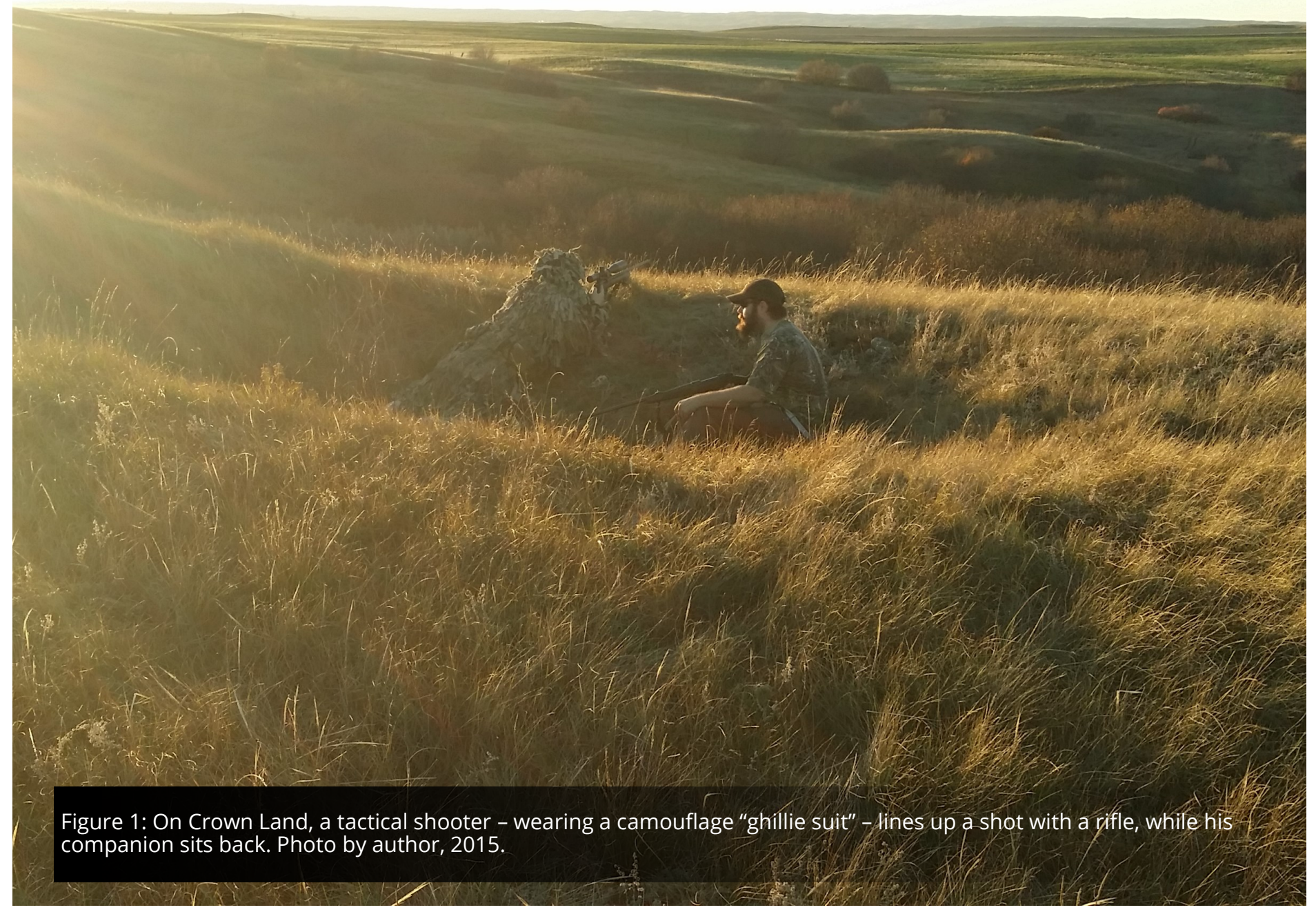

inconsequential compared to their actual shooting, is an important means for understanding what is constructed around shooting, and what my respondents get out of this hobby. While terms like "community" and "comradery" are nebulous concepts that imply more social cohesion and boundaries than actually exist in the world, tactical shooters frequently used these terms to describe their experiences. As such, they can be viewed as ideals that provide insight to the social importance of tactical shooting. Comradery and a strong sense of community are a significant part of what these tactical shooters draw from their leisure group.

I begin with an overview of relevant literature and the importance of narrative talk to my informants' constructions of comradery and collective identity. Following is a discussion of my positionality and the practice of tactical shooting as described by my informants. An outline of the primary narrative form I noted among shooters, the memory story, is then followed by an analysis of its social significance. Throughout such talk, my tactical shooter informants expressed frustration that both "non-shooters" and other members of Saskatchewan's general shooting community do not appreciate, and are sometimes opposed to, their shooting practices. I argue that tactical shooters' particular narrative styles form a sense of togetherness within a broader social context in which they feel doubly misunderstood. The point of shooting narratives is not shooting per se, but is rather the sense of community and comradery that shooters seek to build.

\section{The Importance of Talk}

There is a paucity of ethnographic research on shooting in Canada. Some ethnographies are concerned with social change, landscape, and class (Lorimer 2000; Mischi 2012), but these tend to focus more on hunting practices than on shooting in general. Unsurprisingly, given the proliferation of guns in the United States of 
America, and perhaps due to relatively permissive regulations, most ethnographic research on shooting is carried out among American shooters. Anderson and Taylor (2010) focus on the social bonds formed in shooting communities; Michael Messner (2011) explores the male bonding rituals formed around hunting in American families; and Hoon Song (2010) offers a phenomenological analysis of a particular shooting event, highlighting the subjective experiences of participants. Yet a dominant tendency is to dwell on what are construed as the negative aspects of so-called gun culture (Patrick 2007). Perspectives associating gun ownership with neoliberalism, social conservatism, and "hegemonic masculinity" (Gahman 2015) inform much of the current scholarly research connected with "gun culture." While my informants performed identities that fit with expressions of normative masculinity, and sometimes "conservative" ideas (like criticism of "liberal" gun laws), normative portrayals of gun culture did not neatly fit my experiences in the field.

I developed a distaste for the term "gun culture" because it suggested that a strict set of social norms, including conservatism, whiteness, and a tacit acceptance of violence accompanied gun ownership. The popular use of this term in the media suggests that gun culture is a mainstay in America, and regularly associates this culture with violence and political division (Gollom 2015). While not entirely incorrect, this perspective on gun culture obscures the diverse, regionally-specific forms such culture can take (Kohn 2004). The broad concept of gun culture is unsatisfactory to describe my informants because they do not seem to fit the stereotypes this term suggests. As Dmitra Doukas $(2010,19)$ argues, the popular image of the gun-toting, conservative redneck that so frequently bleeds into academic assumptions is best described as a "bogeyman," not a realistic portrayal of behaviour. She points out that Americans rarely line up neatly along the "culture war front," a sentiment I find also applies to tactical shooters in Saskatchewan.

Although the shooters I met could not be neatly relegated to a monolithic gun culture, working to form a sense of community or comradery was a dominant theme in their storytelling. I suggest that they worked to build a "serious leisure community" of their own. Such a group is formed around "the steady pursuit of an amateur... voluntary activity that captivates its participants with its complexity" (Anderson and Taylor 2010, 36). Serious leisure communities provide participants with a sense of identity and group membership (Rosenbaum 2013). Studying leisure groups can be a means to explore "the creation of social identities in late modern society" (Anderson and Taylor 2010, 35), as such groups give participants a wide variety of opportunities to engage in identity work and form social bonds.

Storytelling is a key component of the serious leisure community my informants construct. Herzfeld's (1985) concept "poetics" is helpful in capturing the yearning for comradery that tactical shooters' stories conveyed. Poetics is understood as the ways in which a story is told and communication is successfully - or unsuccessfully - carried out within a social context. The poetics of communication is performative. Herzfeld explains that a successful demonstration of poetics "concentrates the audience's attention on the performance itself" (1985, 10), allowing the telling of the story to convey meaning just as much as, and sometimes more than, the content of what is being told. Ergo, poetics is the story and the telling intertwined, inextricable from the social context the performers act within and help to construct. With my tactical shooter informants, poetics is the content, the tone, the technical language, the mimed actions, the allusions of inside jokes and, sometimes, the explicit highlighting of their own social values. I argue that this is what makes their stories shooters' stories, they are crucial for constructing and performing their identities as tactical shooters and for constructing a collective identity and a powerful sense of community.

\section{Positionality}

I find it necessary to present my findings in a reflexive manner. Contrary to criticisms that reflexivity emphasizes subjective insights over objective knowledge (Salzman 2002), and that it 


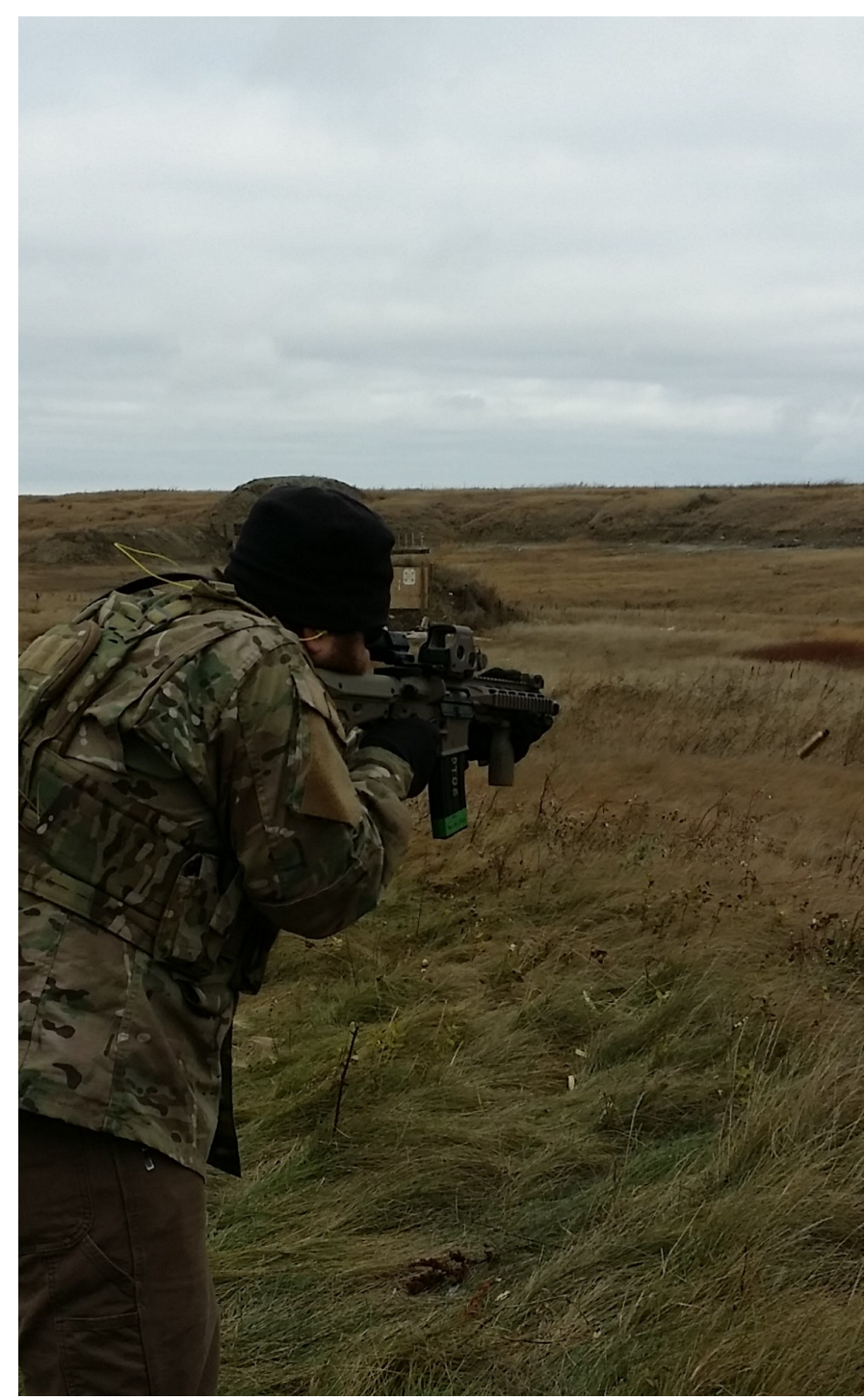

Figure 2: After a shooting match, a man fires shots from a semiautomatic rifle "just for fun" into the dugout of a gun range. The shooter is wearing a camouflage "chest rig" for protection. Photo by author, 2015.

may distance the ethnographer's perspective from the group discussed (Stewart 1996), who I am to my informants and how we interacted with one another are inextricable from the knowledge that my fieldwork produced. I am a "quasi-insider" (Angrosino 2004) of tactical shooting. I do not shoot, but having friends and a boyfriend involved in tactical shooting provided me with relatively easy entry into their leisure world. It also provided me a social identity that members of this group recognized: Jon's girlfriend.

This both enriched and complicated my research. On the one hand, many who were strangers to me knew Jon and could place me quickly, and I suspect this helped counteract my outsider status as a non-shooter. On the other hand, as some ethnographers have noted
(Shuttleworth 2004; Teaiwa 2004), it was sometimes difficult to break free from the social obligations of this identity. Although I was both a researcher and a friend, the latter was often treated as more important by my informants. This resulted in more socializing and "catching up" during fieldwork encounters than I anticipated. My status as a woman in her twenties, studying anthropology at university, may have likewise tinged my interactions in the field. This is because some of my informants seemed circumspect about the motives of social scientists who write about shooters. They said they assumed that academic works on shooting would mostly be negative, "liberal," or "anti-gun." Despite this, my informants seemed to take my willingness to discuss shooting as indication that my approach might not fit their assumptions. As a whole, I suspect my quasiinsider status allowed me to conduct more nuanced research during my short time in the field than if I had been a total stranger to my informants.

\section{Method}

I conducted research with five key informants: Ray, Tim, Daniel, Kevin, and Otto. They were all men in their mid-thirties to mid-forties, and though I did not meet any women who were tactical shooters, it was emphasized to me that women shoot with them as well. Most of my informants were fathers and husbands, had some form of secondary education, and held fairly well-paying working-class jobs. They lived in small cities, although their shooting took place on gun ranges and farms in rural areas. Many of the shooters I encountered were not originally from Saskatchewan, and a few, like Otto, were born outside of Canada. While at the time none of my key informants held jobs that involved shooting, two were ex-military, four had taken policing or security training at a postsecondary institution, and three had previously held positions that required carrying a handgun.

All of my informants practiced shooting "for fun" (Figure 2), but they also used it for "practical" purposes, like helping farmers with pest control. The responses I received when I asked my informants why they liked shooting varied. While all had hunted in the past, few 
said they currently did, and some voiced displeasure with "killing animals when you don't need to." Some shooters discussed their practice as an opportunity for personal growth in addition to a site for comradery; Daniel and Tim discussed tactical shooting as a "martial art," a lifestyle they felt involved discipline, athleticism, and knowledge, but not necessarily violence.

I prepared for fieldwork expecting to study the material items my informants use when shooting, such as their guns and "kits" of supplies. Entering the field turned this idea on its head. I discovered that, while my informants politely answered my questions, they seemed uninterested in discussing the things they used for their hobby. Guns, I was told repeatedly, were tools: useful, interesting to a point, but hardly able to animate shooters like the stories they told of what they did with these tools. Otto colourfully explained this perspective during an evening of socializing. He placed a screwdriver, a pair of pliers, and a handgun in a line on the table we were sitting at. He picked up each item in turn, looked me in the eye, and said - calmly - "this is a tool." Once he set the handgun down, he slapped himself on the chest and said, "/ am the weapon! If I'm going to hurt someone, I could do it just as easily with any of these things. It all depends on how the person holding it acts." Clearly, a handgun presents a greater capacity for inflicting harm than a screwdriver, but Otto illustrated a perspective many of the tactical shooters I met articulated: that it is the actions of people - not necessarily the "tools" they use - that should be central to discussions of shooting. While Otto's statement points to the potential violence of guns, he draws a line between the "tools" being inherently violent and the danger, as Daniel later phrased it, of these tools "being in the wrong hands." In short, despite an interest in guns, my informants articulated that they did not consider these tools as socially central as the experiences they formed with them.

While many shooters in North America pay lip service to this gun-as-tool discourse (Gahman 2015; Springwood 2014), the behaviour of my informants suggests they took this discourse seriously. While I always saw my informants ensure that their handguns or rifles were emptied of bullets before handing them because, I was told, even when a semiautomatic gun is not loaded with a mag it is possible for a bullet to be held in the chamber of the weapon - I witnessed instances where even quite expensive guns were unceremoniously dropped by shooters when they were done using them. Unloaded guns were set on tables, leaned against trees, and left on the ground of outdoor shooting ranges when not in use. Guns were discussed in largely utilitarian terms, with the exception of shooters briefly complimenting a friend's new or uncommon one.

This is not to say that guns were unimportant to tactical shooters, for the enjoyment of using them is a key factor in what drew these men together. A number of my informants had prior weapons training, and tactical shooting was noted by Tim and Otto to be a means of continuing to use guns in ways they enjoyed but no longer needed professionally. Additionally, my informants had all hunted in the past, a common practice in Saskatchewan that is connected to rural and Prairie regional Canadian identities, so gun use was already an acceptable hobby for these men to take up. However, I propose that tactical shooters' use of a gun-related hobby to conduct their identity work is partially rooted in a connection between guns and masculinity. It can be said that my informants use guns as tools not only for their hobby, but also as a means to facilitate close relationships without detracting from their normatively masculine identities.

My previous idea of focusing on materiality having fizzled out, I was at a loss for what to actually study with tactical shooters. Accordingly, I employed a grounded approach. I began my research without a working thesis to guide it, but instead with the intent to pull my key points and research questions from what I encountered in the field. Prospective informants were told that I was an anthropology student who wanted to "write about shooting," but I let them decide where we would meet and what we would do. As a result, my field grew to encompass a large portion of southern Saskatchewan - stretching from Mortlach to Regina and past Avonlea - as I met with informants in fields, on ranges, and 
around kitchen tables. I witnessed informal shoots, and thanks to the generosity of the International Defensive Pistol Association (IDPA) of Sask Tactical, a tactical shooting club, I attended a formal Close Quarters Battle competition (a military style shooting drill that involves both handguns and rifles, and requires participants to shoot at targets from various "short" distances and positions). The bulk of my research, however, was simply "hanging out." It was through this informal approach to research that I picked up on common aspects of the social world of these tactical shooters, and began to notice the significance of storytelling.

During my research I conducted informal group interviews and often followed these up with emails or text messages to clarify my impressions. Sometimes, due to explicit refusals, I was not able to record any audio, so I had to rely on my memory and notes. I recorded data in a notebook and on a word document on my mobile phone. Shooters sometimes allowed me to take videos and photos, and I would occasionally send them my recordings of their adventures which proved to be a means of reciprocating them for their help.

\section{"Sighting in" Shooting}

Since all of the shooters I had known before beginning this research seemed to engage in similar practices, I assumed that my fieldwork would be representative of shooting in general. However, I was surprised to learn that my informants practice a very particular style of shooting: tactical shooting. At first glance, shooting in Saskatchewan ${ }^{1}$ may not seem highly segmented, but my informants explained that it can be roughly split into three types. Long-gun shooting is the most common, involving shotguns and rifles being used for hunting, pest control, and "straight-shooting" target practice. Handgun shooting, I am told, is sometimes frowned upon by non-handgun users, who may say that these guns are too "dangerous" for civilians to possess. This can lead to "range policing," wherein other users of a gun range challenge unconventional shooting practices, sometimes even lobbying for these types of shooting to be banned. And finally, there is tactical shooting, which my informants describe as the most specialized and misunderstood shooting style. Tactical shooting involves the use of both long-guns and handguns, and it was described to me as "dynamic," meaning that shooters and sometimes targets move instead of staying still. Many tactical shooting practices are derived from military and law enforcement exercises, although they are not confined to these styles. My research subjects feel that tactical shooters receive the highest level of mistreatment from other shooters and the most mistrust from the non-shooter population. Some characterized themselves as the "black sheep of the shooting world," and Tim emphasized that other shooters "make us out to be some kind of evil baby killers just for what we like to do!"

This sense of alienation may be rooted in a struggle over how gun use is portrayed. My informants claim that some non-tactical shooters fear the pseudo-military practices of tactical shooting, and believe that their gun use is the only style that is legitimate. In response, some of my informants described gun users who opposed tactical shooting as "fuddy-duds" stuck in old ways of thinking. Daniel and Tim explained that fuddy-duds "buy into media hype" that paints handguns, "black" guns - a term my informants used to describe weapons that "looked scary" from an outsider's perspective - and otherwise unconventional shooting practices as dangerous and unnecessary, hence tactical shooters' black sheep status. This may be related to a struggle over who maintains the image of legitimate gun use in mainstream society. In response to media and social criticism of gun use, some shooters may work to distance themselves from practices that they consider too "violent" or unnecessary, while my tactical shooting informants criticize these shooters for not supporting one another and presenting a "united front." In sum, as Otto told me, my informants felt that the shooters of Saskatchewan could stand to be more of a "community."

\section{"Shooting the Shit"}

The strong connection between shooting activities and leisurely talk, or as some of my informants called it, "shooting the shit," was striking. Regardless of whether they were 
shooting at a range, camping outdoors, or clustered around a table, when these tactical shooters met up their conversation frequently drifted towards storytelling. These narratives almost always had a strong collaborative feel, and I frequently found myself in the midst of a story being told by multiple shooters. The telling of these stories was often dramatic and gregarious, even more so than my informants' stories about other topics. I noted that especially among those I knew well, like Jon, shooters seemed to become much more animated when in groups of mostly other shooters. In short, it seemed like my informants' storytelling was amplified when talking about their hobby with other enthusiasts.

As mentioned earlier, the types of narratives I noticed tactical shooters engaging in tended to take the form of what I call "memory stories." Shooters' stories frequently pertained to past events involving their group. The following anecdote, told by Tim and Ray, is representative of some common aspects of memory stories.

We had just returned to our cars from shooting at rocks in a nearby field. Ray asked me what l'd thought of our venture. "I wasn't sure what to expect," I replied, "I thought there might have been more running."

Ray and Tim laughed, shaking their heads. "We only run when we have to!" Tim said. Then, his eyes lit up and he whipped his head around to face Ray. I learned to note that this type of pause and movement often marked the beginning of a story. "Speaking of which, remember that time with Daniel when we did have to?"

Ray adopted a similarly excited look, and turned his body towards Tim. The two men stood facing one another, with me roughly in the middle, forming a triangle. As they spoke, they directed comments both to one another and to me, although it felt almost as if they were telling a rehearsed story to each other.

"Oh yeah!" Ray looked over his shoulder to me. "The last time when we were out camping, we were walking out of the bush in the morning, heading back to our cars." He mimed a downward motion with his hand, as if showing how they had moved. "Then, all of a sudden, Daniel drops his pack and shoots off running in another direction!" Ray mimed with his index finger the quick running away of Daniel.

"We stopped," Tim continued, miming a "stop" with his hands up near his shoulders, moving his eyes from side to side as if checking his surroundings, "but he was just a goin'! We turned to look at where he was running to, and saw, waaay off in the distance, a lone coyote on the next hill."

"So, since he was going, we had to follow!" Ray added. "But we had so much stuff! So, trying to be as quick as him, I slid off my pack," he motioned slipping the straps of a backpack off his shoulders, then pivoted his body in the direction he had earlier pointed Daniel running towards, "and made to run after him." Ray pumped his arms from side to side, as if running.

"But," Ray looked to Tim, grinning; Tim grinned knowingly back, "I'd forgotten that my backpack was also clipped around my waist! So here I am, trying my hardest to run after this tall, athletic fucker, and my heavy backpack was hanging upside down from my waist, bumping against the back of my legs and nearly pulling down my pants!"

Tim jumped in when Ray stopped, miming the same backpack removal as Ray, "at the same time, I dropped my pack, but forgot about my CamelBak! And that straw is strong! So, my pack is off my back, but the CamelBak's still attached to my chest rig." A chest rig looks a bit like a vest covered with storage pouches on the front and sides, and is used by tactical shooters to store equipment, and in some cases bulletproof inserts, on their bodies. Tim continues, "So now I'm trying to run after them too, but I'm being pulled to the side by my CamelBak." He mimes running in the same direction Ray had, but as if he is being pulled down to one side. Both men laugh.

"Well, by the time we finally got our shit off and got there," Ray continues, "Daniel had already reached the top of the hill and was getting ready to take a shot at the dog." He mimes Daniel's movement of swinging a rifle upwards into a shooting position. Fluidly, Ray also mimes pulling a mag from a belt-pouch, by 
grabbing an invisible item with one hand from near his belt, then moving that item towards the invisible rifle, sliding it "in" the gun's slot with his palm. I recognized these movements from having seen them repeatedly while watching Tim and Ray shoot earlier on.

"And we're all out of breath and busted up, gasping..." Tim adds, doubling over and putting his hands on his knees, as if exhausted, and looking at me, "While Daniel is perfectly calm, looking at us like, 'what's wrong with you guys?!"'

Both men laugh and shake their heads at one another. Then, they moved to continue packing away our afternoon's gear. The story was apparently over. I asked if anyone had "gotten" the coyote, and Ray paused as if thinking back to the event. He then shrugged, indicating that he did not remember or, possibly, that he did not care. "If anyone did, it would have been Daniel!"

$$
\star \star \star
$$

The "running" memory story told by Ray and Tim, about the absent Daniel, highlights many key aspects of shooters' narratives. The form of this story is similar to others I heard. Stories often bubbled from points in a conversation, places in the surrounding landscape, or particular actions. These seemed to spark shooters' memories to begin a tale.

As outlined above, the telling of the event switched back and forth between speakers. This seemed a given to shooters, for they very infrequently interrupted one another; more often, a shooter would tell a part of the story, then pause or look to another shooter for him to continue the tale. Sometimes shooters made it seem as though these stories were for my benefit - by turning to see my reactions, or beginning a tale with "let's tell her..." - but I found that storytellers rarely directed their speech solely to me. It is perhaps more accurate to say that the audience for these tales was everyone present, including the storytellers.

Bringing to mind Herzfeld's (1985) experiences with his Glendiot informants in Greece, there was a certain poetics to telling these tales. Inflection became exaggerated, voices became louder, and gestures turned theatrical when stories were recounted. Certain words would be shouted, enunciated at different speeds, or even said in an altered voice for emphasis. Notably, the body was a key component of this storytelling. Not only did shooters move their bodies to reflect general movements in a story, they also mimed the actions and reactions of the characters they were discussing. Some of the gestures, like imitating running, were easily recognizable. Many others, however, were bodily movements specific to their practices that took nonshooters like me significant effort to follow. Doing mag changes, pulling items from an invisible vest, and loading guns were some of the movements I became familiar with through observation. When I asked informants to clarify my interpretation of an action, they responded, but I do not think it occurred to them to explain these movements otherwise. Such actions seemed to be easily understood by them, and most importantly appeared to enrich their narrative experience. In other words, particular shooting practices were enacted through shooters' storytelling and by using bodily performance, which increased the entertainment value of the narrated story and helped to situate it within the constructed world of "tactical shooting."

It is important to remember that storytellers within a particular social setting are, through their actions, speaking within this setting and continually working to construct, comment on, and reconstruct it (Herzfeld 1985). The content of Ray and Tim's memory story reflects themes I picked up on in the field, forming both commentary on a social event and underscoring certain values - like skilfulness, comradery, and humour - that emerged as components of the shooters' perceived group identity. The emphasis on "comradery," as some of my informants termed it, is particularly prevalent in shooters' tales. As I have highlighted, stories were often about the past adventures of the tactical shooters they knew; however, even when the stories they told involved themselves, shooters rarely made themselves the heroes of the event being discussed. Instead, the heroic figure of memory stories was almost always another shooter. This continual focus on someone else in the group 
may be a discursive means of constructing sociality, of creating a companionable rather than an antagonistic or competitive narrative context. In cases where someone was not present for the storytelling, as with my "running" example, the hero may be that absent person. In cases where everyone mentioned in the story was present, the emphasis instead shifted from person to person, as the shooter currently speaking downplayed their own actions and highlighted the skills of someone else. This was frequently tinged with selfdeprecation on the part of the speaker. Shooters would make jokes about themselves and exaggerate their shortcomings, while simultaneously speaking highly of other shooters and emphasizing their skills.

This tactic did not come across as selfpitying, but rather seemed geared towards complimenting one another. The favour appeared to be returned sooner or later, even if not within the confines of the story being told. At a later date, without knowing about the story told to me, Daniel and others regaled me with tales about Ray's long distance shooting, and Tim's skills with a handgun. I somewhat expected that a hobby so frequently connected with "hegemonic masculinity" (Gahman 2015) might lead to antagonistic, competitive interactions, but tactical shooters' tendency to "talk one another up" surprised me. Three explanations offered by my informants may be illustrative of why competitiveness did not figure strongly in their narratives. Tim explained "it's taboo to talk yourself up; it wouldn't go over well with the others." Daniel said, "it's admirable to know the limits to your own skills." Finally, Kevin emphasized the sociality of talking about shooting, saying "there is a certain comradery that is brought out." Ergo, talking about shooting is not so much about emphasizing oneself, but is about "talking one another up" and creating a sense of comradery.

Storytelling, especially when poetic strategies are employed, is rarely so much about the content of the message as it is about the performance of the message itself (Herzfeld 1985). It is notable that the point of memory stories was not the linear conclusion of them, for as I experienced with Ray and Tim, the outcomes of these narratives - like who shot the coyote - were often not articulated. Rather, the experiences and actions of shooters in the moment being discussed and the skills and values that these stories tended to highlight were key. More generally, memory stories emphasized humorous aspects of shooters' experiences. My informants' tendency to wait for laughter before continuing to talk, to tell parts of stories like punchlines, and to laugh and joke in response to others' statements suggested that what they considered to be entertaining was a significant component of their storytelling.

\section{Analysis: Tactical Talking, or Shooting the Shit}

Analyzing narrative is a productive means for understanding culture from the perspectives of those who experience it (Stewart 1996). The act of storytelling can be a way of constructing a sense of togetherness, of performing and creating a narrative that fits within or represents a social worldview. I argue that my tactical shooting informants' talk is important because it helps them create a sense of togetherness that counteracts the lack of community they perceive among Saskatchewan's recreational shooters.

My informants voice feelings of being doubly misunderstood, both by non-shooters and by shooters who oppose their particular practices. As such, having a group of like-minded people encouraging their valued hobby can foster a powerful sense of fellowship. It is within this context that tactical shooters' poetic emphasis on teamwork and group membership takes on significance. In contrast to normative masculine ideals like competition and individualism, shooters' narratives work discursively to "build each other up," to emphasize their skills, and to foster a sense of emotional closeness. That the ideal of comradery contributes to emotional bonding is at least somewhat acknowledged by my informants. For example, at the end of one night of drinking Tim said to me "I know it's not the right word for your project, but all of this it's really about brotherhood." I propose that this sense of belonging is a significant benefit that these tactical shooters draw from their narrative practices, perhaps as important to the group as the shooting itself. 
While there is no formal definition of who could be part of this loose shooting group, there seemed to be some implicit sense of what exactly being part of tactical shooting meant to my informants. Teamwork, resourcefulness, humility, enjoyment of the practice, and humour were present in shooters' explanations of their group and these values figured prominently in their storytelling practices. Herzfeld's (1985) insight that cultural poetics depends on how well the message is delivered is particularly relevant here. Poetic conventions like theatrical speech, collaborative telling, and "talking others up" were so consistent in my informants' storytelling that I would be greatly interested to see what might happen should a shooter fail to meet these standards. Tim's comment that showing ego would be "taboo" suggests that a violation of these norms within this group might undermine a speaker's status as a real tactical shooter. In short, I found that tactical shooters' performative poetics helped them construct a sense of community and comradery that fit within the cultural "common sense" of tactical shooting (Herzfeld 1985) as well as within broader parameters of acceptably masculine interests.

If the effect of tactical shooters' narratives is that a sense of group togetherness is created, that still does not explain why "community" is sought in the first place. My informants' tactical shooting identities were not the only ones they possessed. However, many of these men considered this identity to be their "most authentic" one (Anderson and Taylor 2010). Shooting and being around other shooters was when my informants said they could truly "be themselves." This makes the affirmation of such leisure identities, which may be commonly frowned upon by mainstream society, especially important for their self-worth. If we look at the fuzzy concept of community as a "system of symbols that individuals use to find a sense of belonging in a highly differentiated society" (Rosenbaum 2013, 643), then it is not such a stretch to say that tactical shooters might locate some of their most emotionally satisfying relationships within their leisure group. Community is an ideal, but it is also a process, and I argue that tactical shooters' narratives are a key part of how they attempt to construct a sense of togetherness.
My informants stressed feelings of fellowship in relation to tactical shooting, a hobby that from an outsider's perspective - is potentially competitive. Part of what attracts these men to use tactical shooting for their identity work is the enjoyment they profess in shooting guns, especially where a high level of skill is required. My informants describe tactical shooting as a more difficult and mentally stimulating practice than conventional straight-shooting, due to the training, dynamic drills, and variety of shooting styles required. That this explanation sets them apart from other shooters in a positive light may help them reframe their "black sheep" status as one of exclusivity, rather than alienation.

The draw of guns themselves may also come into play, especially when society's masculine ideals are considered. Guns have become "a cultural symbol of masculinity" in Canada and the United States (Cox 2007, 147). They are "totemic symbols" (Arjet 2007, 126) that popular culture depicts as objects of masculine desire. Notably, gun use is intertwined with male relationships (Arjet 2007; Messner 2011). Toughness, individuality, and heroism are masculine ideals and are often associated with gun symbolism (Cox 2007), yet the rituals men construct around gun use - like family hunting trips or narrating a day's shooting events around a campfire - often minimize these ideals (Messner 2011). As such, using guns to facilitate male bonding allows men to construct emotional closeness within a context - shooting - that does not detract from a normatively masculine identity. Even when discussing competitions or comparing skills, tactical shooters' narratives prioritize self-deprecation, emphasize one another's skills, and value working as a team of "comrades." My informants practice tactical shooting for many reasons, but the opportunity to construct a sense of togetherness - that may challenge some normatively masculine ideals - within an acceptably macho context may be why they are drawn to shooting as a site for their community and identity work.

My emphasis on the poetics of tactical shooters' narratives, and the ways they used such tactics to construct a particular social world around their shooting practices, is not to 
say that my informants would not find value in spending time with one another if tactical shooting were removed from the equation. Many of them share relationships that predate or extend past their hobby. However, as they continually stressed, tactical shooting remains an extremely important pastime to them, to the point that it can be considered a "social glue" (Mischi 2012) binding them together. I am hesitant to suggest that a sense of togetherness or identity constructed by their narrative performances would be the same if they could no longer engage in their shooting practices. Through analyzing narrative, we can appreciate that tactical shooting is not always about shooting; among other things, it is also about forming a sense of togetherness through narrative and poetics.

\section{Conclusion}

This article has provided an introduction to one group's view of tactical shooting in southern Saskatchewan. Through an analysis of particular forms of narrative, I have shown that members of this "serious leisure community" work to construct a sense of togetherness in a broader social context in which they feel both other shooters and non-shooters misunderstand them. Such togetherness overlaps with values of teamwork, comradery, and shooting skill, which my informants articulated both explicitly and through their poetics of narrative. Although my time in the field was brief, I propose that attention to such poetics, to follow Herzfeld (1985), may be a highly productive means for gaining further insights into this social world.

There is a particular tension that ethnographers, even fledgling ones like me, encounter when faced with how to represent their informants' worldviews in an academic context that may not find such worldviews agreeable. For many, so-called gun culture fits this category. This is why I have focused not necessarily on taking a side in the debates surrounding this topic, but rather on the social actions of the individuals I have encountered who engage in the shooting practices that are, as they see it, misunderstood by outsiders. For my informants, being open about their leisure identities as tactical shooters can be a political act, and I am aware that any effort on my part to write about these identities may also be taken as such. Accordingly, rather than write about the tension surrounding gun use and ownership, I choose instead to highlight that gun users are not a faceless, homogenous mass but are a multitude of individuals with geographical, ideological, and social idiosyncrasies. Additionally, my discussion about tactical shooters highlights the connection between language and community. While tactical shooters' talk features conventions specific to their practices, many close-knit groups use storytelling to establish social cohesiveness and strengthen group membership. Especially where leisure is a primary purpose, the content of the language may be inconsequential compared to the sense of togetherness its use reinforces. This research serves as a case study for how talking constructs community, and specifically how poetics and performance can create cohesion within a somewhat marginalized group. It has been my intention to both enrich ethnographic knowledge about shooting, and to provide a more humanistic and holistic perspective on gun use in the Canadian Prairies. 


\section{Acknowledgements}

I am indebted to my teacher and mentor Dr. Gediminas Lankauskas for his patient guidance. I am also grateful for the University of Regina Anthropology Department's ongoing support, in particular Dr. Susanne Kuehling's. I thank Dr. Chris Kortright, Nathan McAllister, Cheyanne Desnomie, and my Ethnographic Research classmates for their thoughtful feedback on this project. Finally, this research would not have been possible without the friendship of the tactical shooters who welcomed me to their "leisure world." My special thanks to Wes and the SaskTactical International Defensive Pistol Association for allowing me to witness tactical shooting in action.

\section{Endnotes}

Shooting is relatively common in Saskatchewan. According to Royal Canadian Mounted Police statistics for 2014, 9,463 firearms licences were held per 100,000 people (RCMP 2014: fig.3). There were 4,518 registered restricted and prohibited firearms per 100,000 people (RCMP 2014: fig.8), although only handguns and semiautomatic rifles are in this category, as Canada does not require average long guns to be registered. These numbers place Saskatchewan in the higher figures of shooting and gun ownership in Canada, but not above places like the Yukon or Alberta. These statistics do not show that many more people than those with gun licences periodically shoot, such as those who sometimes shoot as a guest at a range or pick up a rifle at a farm. Therefore, shooting is not particularly "exotic" in Saskatchewan, even if tactical shooting is somewhat niche. 


\section{References}

Anderson, Leon and Jimmy D. Taylor. 2010. "Standing Out while Fitting In: Serious Leisure Identities and Aligning Actions among Skydivers and Gun Collectors." Journal of Contemporary Ethnography 39(1): 34-59.

Angrosino, Michael. 2004. "Disclosure and Interaction in a Monastery." In Anthropologists in the Field, edited by Lynne Hume and Jane Mulcock, 18-31. New York: Columbia University Press.

Arjet, Robert. 2007. "'Man to Man': Power and Male Relationships in Gunplay Film." In Open Fire: Understanding Global Gun Cultures, edited by Charles F. Springwood, 125-140. Oxford: Berg Publishers.

Cox, Amy. 2007. "Aiming for Manhood: The Transformation of Guns into Objects of American Masculinity." In Open Fire: Understanding Global Gun Cultures, edited by Charles F. Springwood, 141152. Oxford: Berg Publishers.

Doukas, Dimitra. 2010. “Targeting the Gun Question: The 'Culture War' in Scope." Anthropology Now2(3): 19-30.

Gahman, Levi. 2015. "Gun Rites: Hegemonic Masculinity and Neoliberal Ideology in Rural Kansas." Gender, Place \& Culture 22(9): 1203-1219.

Gollom, Mark. 2015. “Gun Culture Runs Deep in the US and Won't Change Soon." CBC News. Accessed November 15, 2015.http:// www.cbc.ca/news/world/gun-culture-runs-deep-in- the-u-s-andwon-t-change-soon-1.3127809

Herzfeld, Michael. 1985. The Poetics of Manhood: Contest and Identity in a Cretan Mountain Village. Princeton: Princeton University Press.

Kohn, Abigail. 2004. Shooters: Myths and Realities of America's Gun Cultures. Oxford: Oxford University Press.

Lorimer, Hayden. 2000. “Guns, Game and the Grandee: The Cultural Politics of Deerstalking in the Scottish Highlands." Ecumene 7(4): 403-431.

Messner, Michael. 2011. King of the Wild Suburb: A Memoir of Fathers, Sons, and Guns. Austin: Plain View Press.

Mischi, Julian. 2012. "Contested Rural Activities: Class, Politics, and Shooting in the French Countryside." Ethnography 14(1): 64-84. 
Patrick, Brian. 2007. "Shooters: Myths and Realities of America's Gun Cultures." Review. Journal of Popular Culture 40(2): 395-396.

Patrick, Brian. 2008. "Gun Show Nation." Review. Journal of Popular Culture 41(4): 732 - 734.

RCMP. 2014. "Facts and Figures (October - December 2014)". Webpage. Royal Canadian Mounted Police. Accessed November 20, 2015. http://www.rcmp-grc.gc.ca/cfp- pcaf/facts-faits/indexeng.htm

Rosenbaum, Michael. 2013. "Maintaining the Trail: Collective Action in a Serious-Leisure Community." Journal of Contemporary Ethnography 42(6): 639-677.

Salzman, Philip. 2002. "On Reflexivity." American Anthropologist 104 (3): 805-813.

Shuttleworth, Russell. 2004. "Multiple Roles, Statuses, and Allegiances: Exploring the Ethnographic Process in Disability Culture." In Anthropologists in the Field, edited by Lynne Hume and Jane Mulcock, 46-58. New York: Columbia University Press.

Song, Hoon. 2010. Pigeon Trouble: Bestiary Biopolitics in a Deindustrialized America. Philadelphia: University of Pennsylvania Press.

Springwood, Charles. 2014. "Gun Concealment, Display, and Other Magical Habits of the Body." Critique of Anthropology34(4): 450471.

Stewart, Kathleen.1996. A Space on the Side of the Road: Cultural Poetics in an "Other" America. Princeton: Princeton University Press.

Teaiwa, Katerina. 2004. "Multi-Sited Methodologies: "Homework" in Australia, Fiji, and Kiribati." In Anthropologists in the Field, edited by Lynne Hume and Jane Mulcock, 216-234. New York: Columbia University Press.

Van Maanen, John. 1995. Representation in Ethnography. Thousand Oaks: Sage Publications, Inc. 